\title{
Paleoecology of the first Devonian-like sclerobiont association on Permian brachiopods from southeastern Mexico
}

\author{
Miguel A. Torres-Martínez, Olev Vinn, and Lourdes Martín-Aguilar \\ Acta Palaeontologica Polonica 66 (1), 2021: 131-141 doi:https://doi.org/10.4202/app.00777.2020
}

This paper describes a sclerobiont association from the Paso Hondo Formation (Roadian, middle Permian), Chiapas, Mexico. Different marine invertebrates such as hederelloids, microconchids, bryozoans, and crinoids (represented by holdfasts) encrusted brachiopod shells belonging to Athyridida and Rhynchonellida. This association is similar to those recorded in different Devonian localities, especially by the co-occurrence of microconchids, hederelloids, and bryozoans. Paleoecological analysis revealed that bryozoans were the most abundant sclerobionts, whereas crinoid holdfasts were uncommon. Likewise, hederelloids and microconchids often settled on hosts previously colonized by bryozoans. Most microconchids encrusted rhynchonellid shells. A positive correlation between the size of the hosts and abundance/diversity of sclerobionts was recorded. The distribution analysis suggests that sclerobiont colonization could have been influenced either by inhalant currents of brachiopods, time of exposure, position of hosts, or by combination of all these factors. Moreover, most of commissures and foramens of brachiopods were not covered by epibionts, suggesting that there was a live interaction. Thus, studied brachiopods were likely encrusted syn vivo, and the interaction between sclerobionts and their brachiopod hosts was likely commensal since there is no damage to the brachiopod valves in the form of malformations or borings. On the contrary, the epibiont cover might have served as a natural shield against predators and parasites. The Roadian age of the association is based on the stratigraphic distribution of host brachiopods. The studied association inhabited open waters on a homoclinal carbonate ramp in the Chicomuselo region. Although encrusted brachiopods belong to the biotic Grandian Province, similar sclerobiont communities have not been previously recorded from the Permian of North America or beyond. The described community represents the youngest record of co-occurring microconchids, hederelloids, and bryozoans, as all previously known similar communities originate from the Late Devonian.

Key words: Brachiopoda, Bryozoa, Hederelloidea, Microconchida, Permian, Roadian, Mexico, Chiapas.

Miguel A. Torres-Martínez [miguelatm@geologia.unam.mx], Departamento de Paleontología, Instituto de Geología, Circuito de la Investigación Científica, Colonia Universidad Nacional Autónoma de México, Avenida Universidad 3000, Alcaldía Coyoacán, 04510, Mexico City, Mexico. Olev Vinn [olev.vinn@ut.ee], Department of Geology, University of Tartu, Ravila 14A, 50411, Tartu, Estonia. Lourdes 
Martín-Aguilar [lourdm01@ucm.es], Máster Universitario en Paleontología Avanzada. Departamento de Paleontología, Facultad de Ciencias Geológicas, Universidad Complutense de Madrid, campus Moncloa, Calle José Antonio Novais, 12, 28040, Madrid, Spain.

This is an open-access article distributed under the terms of the Creative Commons Attribution License (for details please see creativecommons.org), which permits unrestricted use, distribution, and reproduction in any medium, provided the original author and source are credited.

FoF Full text $(719.9 \mathrm{kB})$ 